\title{
Evaluation on the Market Strategies of Chinese Medical Service
}

\author{
Hongqiao Yu \\ SAIC GM Wuling Automobile Co., Ltd \\ Liuzhou city, Guangxi Province, China \\ E-mail: Hongqiao.Yu@sgmw.com.cn
}

\begin{abstract}
The purpose of this report is to discuss the medical service of China and improve it through evaluating the marketing strategies and finding resolving methods for the marketing issues and problems which caused by the external and market forces in medical service of China.

In this report, firstly, the introduction of background of Chinese medical service is given. Secondly, some marketing knowledge and theories are reviewed. Thirdly, some problems and issues of Chinese medical service are identified. Then, the external and market forces are assessed based on relative theories. Next, marketing strategy is evaluated to improve the efficiency of Chinese medical service. Finally, conclusion and recommendations are given based on analysis.
\end{abstract}

Keywords: Medical service of China marketing strategy, SWOT, PEST

\section{Introduction}

The purpose of this report is to discuss the medical service of China and improve it through evaluating the marketing strategies and finding resolving methods for the marketing issues and problems which caused by the external and market forces in medical service of China. This correlative information was collected through various journals and newspaper I read as well as other media that I observed. This report will give the recommendation to senior officials of the Central Government of the People Republic of China as they reform regulatory policy to improve the efficiency of medical service based on analysis about the marketing strategy and issues.

In this report, firstly, the introduction of background of Chinese medical service is given. Secondly, some marketing knowledge and theories are reviewed. Thirdly, some problems and issues of Chinese medical service are identified. Then, the external and market forces are assessed based on relative theories. Next, marketing strategy is evaluated to improve the efficiency of Chinese medical service. Finally, conclusion and recommendations are given based on analysis.

\section{Background of Chinese medical service}

Big different condition of medical service exists between cities and countryside in China. Basic medical service can be guaranteed in most Chinese cities, especially those with large cities. However, quality of service may vary between geographic regions. The condition of medical facilities in the countryside is generally worse than in the city, where there are many critical care hospitals, but with the economic development of China, the condition of medical service of countryside is improving rapidly. Although in the same city, there are different level hospitals which have different medical facilities, qualified doctors, services and customers.

However, there are some common features in Chinese medical service. Firstly, medicine shop is set in hospital. Every hospital has owned medicine shop. Health care centre and hospital integrates diagnosis, physical examination, treatment and medicine sales. Secondly, health facilities now rely more on users, fee-for-service payments to raise revenue without the government increasing its direct investment. Next, Prescription drugs and diagnostic/treatment technologies are now regulated by a cost-plus-price mechanism. This mechanism was an incentive to health care centre providers to provide more services and improve their productivity. It also encouraged providers to use more expensive services that generate more revenue. Then, all of patients have to charge for register before every diagnosis, and vary charge depends on different medical health care centre or hospital. Finally, every famous hospital locates the centre of city, such as Beijing Xiehe Hospital, Shanghai Renai Hospital, Xian Xijing Hospital and Shenzhen Fuhua I.T.W.M Hospital.

\section{Marketing theories}

\subsection{Marketing Strategy}

"Marketing strategy indicates the specific markets towards which activities are to be targeted and the types of competitive advantage to be exploited." (Fifield, 2007 p.12) In the light of Poter, there are three generic strategic 
alternatives open to organisation (see the figure 01). The organisation which decides and then consistently follows one of these three prime strategies successfully will achieve good profits and above-average returns on its investment.

\section{Insert Figure 1 Here}

"The organisation that wishes to pursue a strategy of differentiation will be operating throughout the complete market rather than addressing one or two specific segments of the marketplace." (Fifield, 2007 p. 98) "Cost leadership means the organisation can do everything in its power to drive its cost base down to the point at which it is able to produce products or services at a lower cost than any of its competitors." (Fifield, 2007 p. 99) It is significant that lowest cost does not mean lowest price. Focus means that organisation is pursuing a focused strategy makes its effort; it does not pursue the entire market as in the case of the cost leadership and differentiation, but just focuses on one or more specific market segments. 'Stuck in the middle' means that there is no clear differentiation between competitors. Also, there is no price competition following.

\subsection{Marketing elements}

Market strategy has been integrated into the strategy of organisation in modern enterprises; it is one of the business strategies, and it is the bridge of business strategy and marketing planning, it is the order of marketing planning. It is shown as below figure 2 .

\section{Insert Figure 2 Here}

"Marketing is a social and managerial process by which individuals and groups obtain what they need and want through creating and exchanging products and value with others.” (Kotler et al. 2003) Marketing's main tasks are focused on identifying and satisfying customers' needs, and making it has more attraction than its competitors. These tasks are reached through the marketing mix's application, an elements' combination that the offering actually is created. Marketing mix includes four elements for most physical goods: product, price, place, and promotion. For services, it can be extended to seven elements plus processes, physical evidence and people.

The Product, it covers everything and it includes tangible products (physics goods), intangible products (service) and ideas (commercial messages, for example). It is at the heart of the marketing exchange. If the products does not deliver the benefits the customers wanted or if it does not meet the expectations of the other marketing mix, which means that this organisation is fail to introduce these products, and the marketing strategy could be not supported by these products. The Price, it is interesting and easy understanding element of the marketing mix. However, it plays a very important role in marketing strategy. Price can reflect the issues of buyer behaviour. Price can be used as a competitive weapon. The customers can use price as a means of comparing products, judging relative value for money or judging product quality. The Place includes company activities that make the product available to target consumers. It concerns the movement of goods through the various channels of distribution to the eventual customer. It is important to access to channel management, target market, channel structure, chosen channels' image and logistics. The Promotion, planning and managing the communication with the marketplace. Considering the available techniques of communication, each objective can be achieved, their relative weaknesses and strengths, and the planning processes and management that have to support them. So it is important to emphasize direct marketing, advertising management, developing Promotional Mixes, public Relations. The People, no people no service, the product customer wanted can be created and delivered by people. So it is significant to stress adding value to the marketing package beyond the basic product offering. The Processes, "Procedure, mechanisms and flow of activities by which services are consumed (consumer management process) are an essential element of the marketing strategy." (Kumar, 2004) The Physical Evidence, "the ability and environment in which the service is delivered." (Aaker, 2007) It refers to environment, medium, image and design of premises can be significant in numerous service marketing.

\section{Identify the issues and problems}

\section{Insert Figure 3 Here}

In this part, the main issues of Chinese medical service will try to be identified and described. Based on the 'SWOT' analysis (see the figure 03) and in the light of marketing elements (see the figure 04), the first issue is the place. There is big different condition of medical service between urban area and countryside. The second issue is the price, and higher price has been a burden of Chinese to a patient. The next issue is the product. The Chinese medical service offers two kinds of products which are dissatisfied by customers. One product is medicine and drugs. Another one is the service which is special product. The final issue is the people. Customers are dissatisfied with medical staff's attitude and service. These issues are identified based on the weight of effects on the patients and Chinese market-orientation medical service. These issues are integrated into 
complicated problem for Chinese government, and it is difficult to solve it in short time.

Insert Figure 4 Here

\subsection{The place issue}

The place of medical service is the biggest problem for Chinese. On the one hand, there is great difference in quality of medical service and medical facilities due to different geographic region of China. China is the biggest country in the world, and people in mountain area and plain area have varied economic level of development. The western and eastern China also has different medical condition, as well as urban people and people live in countryside. Critical medical condition emerges in underdevelopment area, such as lack of medical facilities, medicines and doctors in countryside, mountain area and western of China. For some patients who live in underdevelopment area with serious disease, they have to trudge for long distance for treatment. On the other hand, basic medical service can be guaranteed in most Chinese cities, but most of hospitals or health care centres are locate in the centre of city or commercial area rather than residential area. That is not convenient for patients in transportation and parking, especially for urgent patients, and treatment time equal to their life. Therefore, the voice of 'it difficult to see a doctor' usually could be heard in China.

\subsection{The price issue}

The price of medical service is another headache issue for Chinese. There are some reasons why the price of medical service so high. Firstly, extra physical examination causes high price of medical service. In China, health care centre and hospital integrates diagnosis, physical examination, treatment and medicine sales. Health facilities now rely more on users, fee-for-service payments. Patients have to receive more extra physical examinations in order to meet health care centres' or hospital's revenue and profits. Because patients have no professional knowledge and do not know weather it is need or not. Next, extra medicine expense is added to the patients. Every hospital or health care centre has owned their medicine shop. Doctors not only are responsible for treatment, but also medicine sales. Medical staff usually sells extra medicine to patients for increasing their profits. They often replace less profitable with more profitable medicine and can prescribe large quantities of medicine for generating a higher profit. Finally, the medicine price of hospital is much higher than markets'. In order to sell their medicine to providers, these manufacturers engage in intensive marketing, which includes kickbacks and bribes. (Wang et al, 2007) As a result, medicine cost has increased greatly, which cause high medicine price. Therefore, also the voice of 'it is expensive to see a doctor' could be heard in China.

\subsection{The product issue}

"Product means the goods-and-service combination the company offers to the target market." (Kolter and Armstrong, 1999 p.49) "In fact, all physical products contain an element of service, and all services contain an element of physical product." (Blythe, 2006 p.88) Medicine is the product offered of health care centre or hospital besides medical service. Customers are dissatisfied with the quality and safety of medicine. At first, in some devious countryside, some expired medicines are still applied for local patients whose lives are suffering from threats by these expired products. Next, some fake medicines also are used for patients in poor mountain area due to government's inefficient monitoring and some doctors want sudden huge profits with illegal trades. Sometimes bad news about death for fake medicine is come out from devious mountain region of China. As a consequence, Chinese people have much complaint about the quality of medicine, sometimes they refuse to treat in local clinic because of worrying about medicine quality.

\subsection{The people issue}

People play a crucial role in marketing elements, and its issue is also apparent in Chinese medical service. Firstly, medical staff is short in Chinese medical market especially high technical person with ability in treating and defending cancers. China is the large country with 1.3 billion populations. There is lacking of medical staff with qualification in underdevelopment area of China. Secondly, the attitude of medical service could not be accepted happily in some monopolizing medical area. Some patients have to bribe doctors in charge of a case to get better treatment. Patients and their relations are dissatisfied with medical staff's attitude and service. As time passes, they lose their trust step by step in these hospital and medical service care. "The hospital trusts will earn revenue from the service they provide. They therefore have an incentive to attract patients, so they will make sure that the service they offer is what patients want." (Sheaff, 1995 p.1) Finally, some man-made factors lead to poor persons who cannot receive equalled medical service system. Because of medical service cannot provide services to people who cannot pay for them.

\section{Assess the external and market forces}

China is in a critical stage of reforming its health care system. It is helpful to solve issues of medical service if it 
can rein in market forces of the medical service through regulations made by government. The traditional 'PEST' analysis includes four headings that create the mnemonic Political, Economic, Sociological and Technical issues. In this part, we will analysis these factors that caused these above issues of Chinese medical service (see the figure 05).

Insert Figure 5 Here

\subsection{Political factors}

In China, political factors have greatly impacted on medical service industry, also caused some issues discussed above, such as price, products and people issues. One is many ministries are involved in managing the health system lead to unclear responsibilities between them. At least eleven ministries are involved in medical service business in China, mainly are the Ministry of Health (MOH), National Development and Reform Commission (NDRC), Ministry of Finance (MOF), Ministry of Labor and Social Security (MOLSS), Ministry of Agriculture (MOA), Ministry of Civil Affairs (MOCA), Administration of Chinese Medicine (ACM), State Food and Drug Administration (SFDA), and the General Administration of Quality Supervision, Inspection, and Quarantine. For example, SFDA and the $\mathrm{MOH}$, both of which are responsible for the safety and quality of medicine. These multiple management within across agencies leads to fake products coming out and high price of medicine. Another is that permitted markets which including the licensing of hospitals, doctors, and pharmaceutical factories. The Chinese government currently supervises in market entry, but the implementation of regulations is not stern.

\subsection{Economic factors}

Economic factor also is one of the factors that cause the medical service issues. First of all, it can cause the issue of place in medical service. The GDP of China increases rapidly with over $8 \%$ every year, fast development of economy does not match with the construction of medical system. Also the regional economic development is not balanceable, and the medical service difference is great between urban and countryside area. Some people who live in devious underdevelopment region feel that it is difficult to receive medical service. Next, it can cause the issue of product (medicine or drugs). In order to develop local economy, some fake drugs are produced sold by illegal medicine factory with local government protection. Finally, the increasing of economic development can cause the high price issue of medical service. With the development of economy, buying power of people is increasing for their income rising. Part of them can afford more expense of medical service with higher price, another part do not. Therefore, high price become an issue of medical service brought by economic development.

\subsection{Technical and sociological factors}

Technical and sociological factors can cause medical service issue of price and people. On the one hand, the costs of technical protection eventually will be reflected on the price of medical service. For example, patents and copyrights fares. On the other hand, the great population of China needs more medical staff, especially medical expert with high technical ability. Therefore, the issue of medical service shortage still has been in short time.

\section{Evaluate the market strategies}

The essence of good market strategy is to anticipate and identify what our customers want and then be in the right place at the right time to be able to offer the right product/service to the right people. (Fifield, 2007) In the light of Poter's generic strategies which introduced in theory induction part, Chinese government not only values cost leadership, but also focus on product's quality and safety of medical service (see the figure 06). "Strategies are built on a solid foundational understanding of the organisation's mission." (Dwyer \& Tanner, 2006 p.161) The government of China is trying to provide safe, effective, convenient and low-cost public health and service to both rural and urban citizens. With these instructions of medical strategy, Chinese government adopted a serial of medical policies and reforms in order to realize its strategic objectives. For example, market-orientation reform, market-based incentives, permitted markets, pricing and product policy. These policies are playing certain roles on ensuring the fairness of medical service, correcting the failures of market in the delivery system, and ensuring medical equity in the delivery. However, current medical issues still have impact on reaching its medical strategy. Such as, 'it is difficult and expensive to see a doctor for ordinary citizen'. Therefore, China developed some strategies to attempt to resolve these problems.

\section{Insert Figure 6 Here}

Firstly, China has established two sets of strategies to solve the place issue. The purpose of the first set is to ensure a sufficient supply of services in devious regions. For this, large hospitals located in urban areas are required to support hospitals or clinics located in mainly rural areas. The reason for the second set of regulations 
is to make sure that patients are not refused emergency services if they are unable to pay for them. But who should cover the costs of services for patients not able to pay for them is still being debated. A systematic assessment of the results of both sets of strategies has not been undertaken. In order to achieve greater equity, the government should establish a safety net of basic health services for the poor. This safety net includes regulation as well as direct government financing and the provision of services.

Secondly, the central government has issued regulation to solve price issue of medical. In China, the governments regulate prices, and then the Bureau of Pricing in each provincial government actually sets the prices of medical services and drugs in that province. In order to reduce patients' burden to pay for medical services, governments at both levels announced, for example, several reductions in drug and medical service prices. Because the providers choose which drugs to prescribe and in what quantities, they also can replace less profitable with more profitable drugs and can prescribe large quantities of drugs in order to generate a higher profit. But without rigorously implementing the regulation and changing the incentives to limit prescriptions and the profits from them, price regulation cannot ensure that patients or third parties money is spent effectively. Therefore, the government should set price monitor system to ensure patients' money is spent effectively.

Thirdly, the government hopes to solve effectively the issue of product quality though permitted license. Drug production is licensed by agencies in the provinces, each of which is equivalent to the U.S. Food and Drug Administration (FDA). These agencies are responsible for controlling drug quality only within the province, even though the market for most drugs covers the entire country. These provincial agencies try to balance the tension between drug quality control and the contribution of pharmaceutical factories to local economic development.

Finally, Chinese government is planning to solve the issue of limited human resources. First of all, the government is organizing volunteers of medical service to support rural medical service from urban health care centre and hospitals. Secondly, government has issued the regulation to manage strictly qualifications of doctors, and will beat sternly illegal doctor all of the country. In addition, government encourages graduates to work in countryside with favourable policy. However, it as if is not effective for improving current status. One reason is that the training and efficiency of regulatory personnel are not as effective as they could be. Another reason is that good regulatory practice also requires that officials have high moral standards, which are difficult to maintain in many environments and regulatory situations. In other word, these strategic measures do not solve completely the shortage of medical staff.

\section{Conclusion}

The aim of this report is to discuss the medical service of China and improve it through evaluating the marketing strategies and finding resolving methods for the marketing issues and problems which caused by the external and market forces in medical service of China. In this report, firstly, the introduction of background of Chinese medical service is given. It mainly includes the status of Chinese medical service which is described as the different medical condition between urban and rural area. Secondly, some marketing knowledge and theories are reviewed. Such as marketing strategy and marketing elements. Thirdly, some problems and issues of Chinese medical service are identified based on marketing elements and the 'SWOT' analysis. Then, the external and market forces are assessed based on 'PEST' analysis from political, economic, sociological and technical aspects. Next, marketing strategies of Chinese medical service is evaluated in order to improve the efficiency of Chinese medical service, which focus on medical service problems. For example, place issue, price issue, product issue and people issue.

Looking to the future, there will be two main features in Chinese medical service industry in the future. One feature is the gap of medical condition between urban and rural area will be reduced. At first, the government is reforming rural medical system including restructure clinics into the centre of medical service to offer effectively more perfect service to local residents. In addition, with the economic development of countryside, their economic condition will be improved, which will enhance local medical level. Another feature is online service become more and more popular, especially the treatment and consultation in psychological aspect. With the development of internet technology and the popularisation personal computer, increasing patients are getting treatment from internet by medical experts. However, it cannot replace actual health care centre and hospitals.

\section{Recommendation}

In the light of above description and analysis, some recommendations about Chinese medical service should be given. Firstly, the central government should define clear marketing strategy for the development of medical service. Not only can it provides safe, effective, convenient and low-cost public health and service to both rural and urban citizens, but also need to balance improvement of the population safety, health and protection of 
medical services with economic development. As well as using regulation restrict providers' behaviour is driven firstly by consideration of their patients health and safety, then secondly by individual interests. Besides, medical policies should ensure the objective selection of medical service and medicine treatment options independent of financial conflicts. Secondly, regulatory policies should be improved, especially in medicine regulating and managing qualification of doctor. Thirdly, the government should use its power to enhance the implementation of regulatory policies to achieve strategic objectives. Through its direct investment in the delivery of medical services and through the provision of funds for health insurance, the Chinese government has become a major stakeholder in the country health care. Chinese policymakers can learn from other countries experiences about ways to use the government purchasing and investment power to help implement regulatory policy in the public interest. Finally, the government should establish science-based regulatory system that draws on other countries recent experiences to assemble the best available evidence to inform regulatory policy. Effective regulatory system requires an evidence-based policy, a transparent information system, and corrective measures that rely heavily on education to change providers' behaviour. Also, restructuring regulatory policy and its implementation, especially by multiple government agencies scattered throughout the country. This includes separating the government role in regulating medical services from its ownership of facilities that provide services.

\section{References}

Aaker, D. A. (2007) Strategic Market Management [online]. Available at: http://www.12manage.com (Accessed: 16 April 2008)

Blythe, J. (2006) Principles \& Practice of Marketing, London: Thomson Learning.

Brassington, F. \& Pettitt, S. (2003) Principles of Marketing, 3rd edn. Harlow: Pearson education limited.

Dwyer, F. R. and Tanner, J. F. (2006) Business Marketing: Connecting Strategy, Relationship, and Learning, 3rd edn. New York: McGraw-Hill/Irwin.

Fifield, P. (2007) Marketing strategy: the difference between marketing and markets, 3rd edn. Oxford: Elsevier Ltd.

Kotler, P., Armstrong, G. (1999) Principles of Marketing, 8th edn. New Jersey: A Simon \& Schuster Company.

Kumar, N. (2004) Marketing as Strategy [online]. Available at: http://www.12manage.com (Accessed: 16 April 2008)

Sheaff, R. (1995) Marketing for health service, Celtic Court: Open University Press.

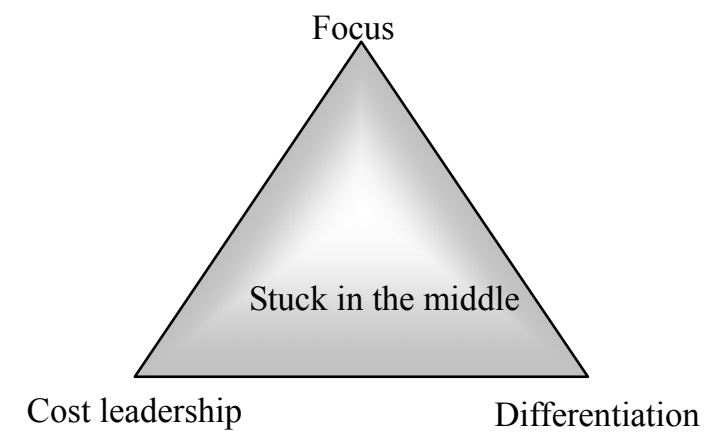

Figure 1. Poter's Generic Strategies

Source: Poter (1983) 


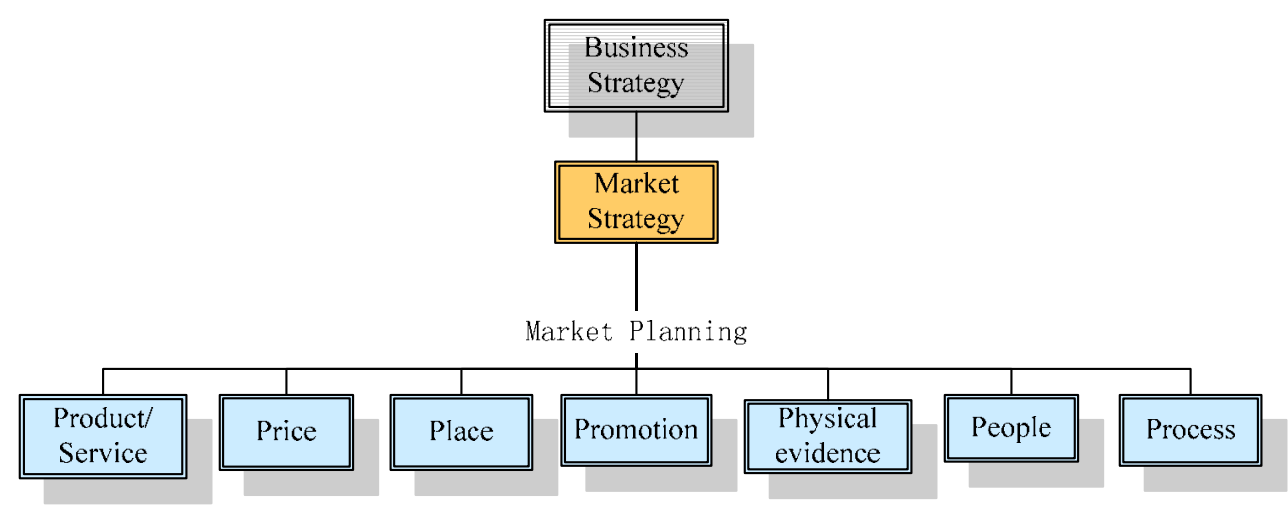

Figure 2. Strategy and Marketing (Fifield, 2007)

\begin{tabular}{|c|c|}
\hline $\begin{array}{l}\text { Strength } \\
\text { - } \quad \text { Great economic increasing } \\
\text { - } \quad \text { The great population } \\
\text { - } \quad \text { Market-orientation medical service }\end{array}$ & $\begin{array}{ll}\text { Opportunities } \\
\text { - } & \text { Great economic increasing } \\
\text { - } & \text { Stable political environment } \\
\text { - } & \text { IT technical application } \\
\text { - } & \text { Organization restructuring } \\
\end{array}$ \\
\hline $\begin{array}{l}\text { Weakness } \\
\text { - } \quad \text { Not balanceable region development } \\
\text { - } \quad \text { Multiple managing sectors } \\
\text { - } \quad \text { Short of medical staffs } \\
\text { - } \quad \text { Inefficient supervise for implementation of regulation }\end{array}$ & $\begin{array}{l}\text { Threats } \\
\text { - } \quad \text { High price } \\
\text { - } \quad \text { Product quality and safety } \\
\text { - } \quad \text { Implementation of regulation is not rigorous }\end{array}$ \\
\hline
\end{tabular}

Figure 3.The SWOT Analysis of Chinese Medical Service

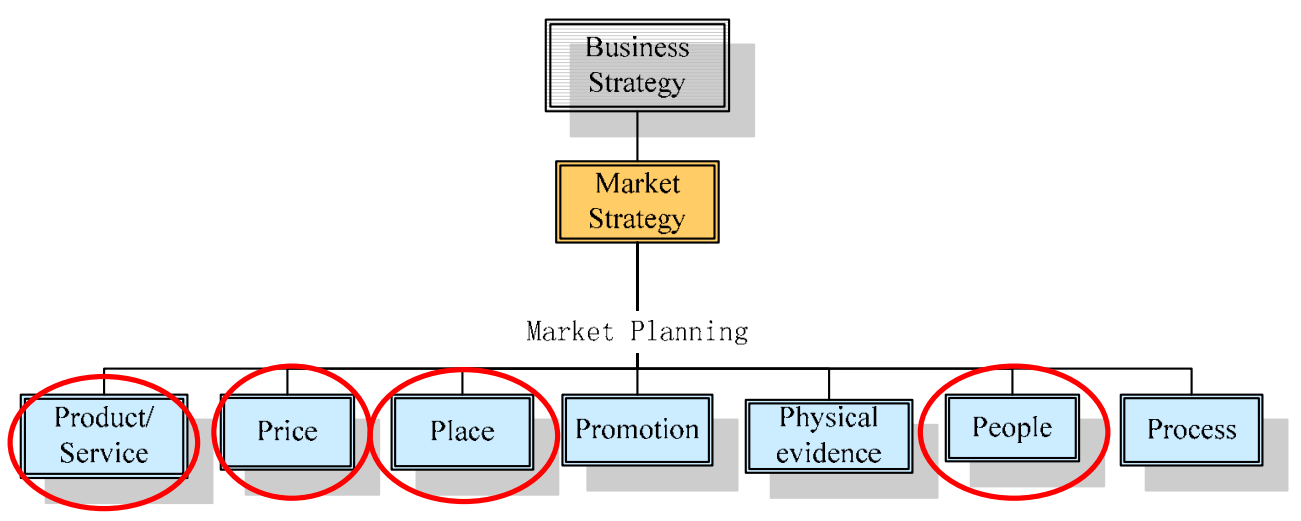

Figure 4. Identifying Issues of Medical Service 


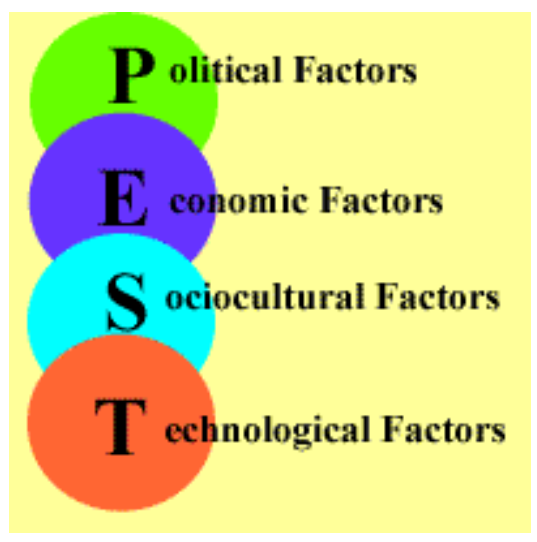

Figure 5. The PEST Analysis

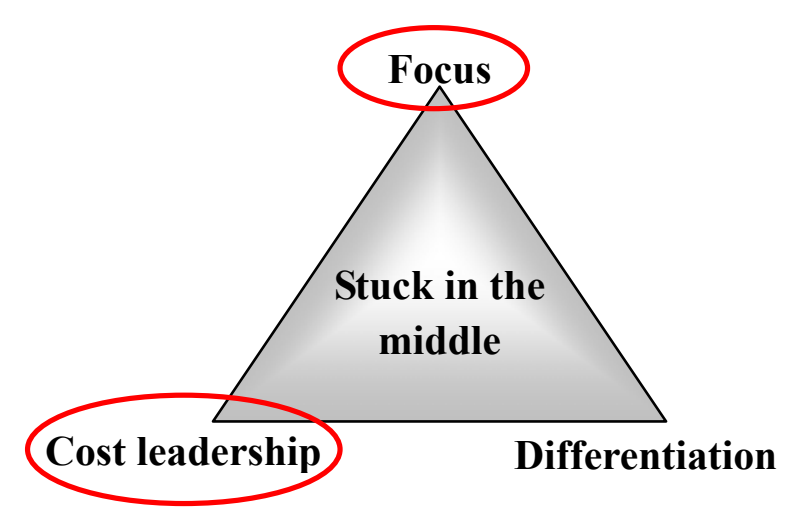

Figure 6. Chinese Medical Service Strategies 